\title{
Complexities of Implementation: Oxfam Australia's Experience in Piloting Blockchain
}

\author{
Joshua Hallwright* and Elsa Carnaby \\ Oxfam Australia, Melbourne, VIC, Australia
}

This paper describes one of Oxfam's pilot projects exploring blockchain technology, focusing on the non-technological, institutional challenges faced by the organization. There is an emerging literature on blockchain for social good, however, this predominantly focuses on the use cases and issues relating to applying the technology in international development projects. A gap in the literature exists regarding the non-technological

OPEN ACCESS

Edited by:

Zachary Baynham-Herd, University of Edinburgh,

United Kingdom

Reviewed by:

Raul Zambrano,

Independent Researcher, New York

United States

Sean T. Manion,

Science Distributed, United States

${ }^{*}$ Correspondence:

Joshua Hallwrigh

joshh@oxfam.org.au

Specialty section: This article was submitted to

Blockchain for Good

a section of the journal

Frontiers in Blockchain

Received: 30 April 2019 Accepted: 15 August 2019 Published: 28 August 2019

Citation:

Hallwright $J$ and Carnaby E (2019) Complexities of Implementation: Oxfam Australia's Experience in Piloting Blockchain.

Front. Blockchain 2:10. doi: 10.3389/fbloc.2019.00010 aspects of blockchain projects both within the sector and more broadly. Addressing this gap is critically important as many of the promises of blockchain technology will only eventuate in their fullest when whole ecosystems are using the technology. To get there requires a transition period and it is this transition period that holds the key to success for organizations exploring the technology. This paper goes some way to addressing this gap. It does so by describing a specific case study and unpacking some of the organizational challenges associated with implementing a blockchain-based project in the international development and humanitarian sector. This has important implications for the sector as blockchain technology becomes ever more present as a tool capable of reducing inequality and addressing power imbalances. The Oxfam case study described in this paper highlights the difficulty many not-for-profits are having engaging with the technology. The lessons are drawn from a specific use case of a current pilot project using blockchain technology in a cash transfer preparedness project in a small island developing state. Although important and insightful, this paper does not focus on the specifics of the application of the technology but rather discusses the myriad non-technological challenges faced from Oxfam Australia's perspective. These are categorized into three main areas: awareness and understanding of the technology, capacity constraints of in-house support services in providing relevant support for a nascent technology, and issues related to engaging in non-traditional partnerships. The paper concludes by recommending further areas of research and suggestions to develop practical tools and guidance to help the international development and humanitarian sector navigate this emerging technology.

Keywords: International development, humanitarian action, cash transfer program, non-government organization, pilot 


\section{INTRODUCTION}

Along with many other sectors, the international humanitarian and development sector is exploring the opportunities that blockchain technology ${ }^{1}$ promises. The sector is not as advanced as some others-such as the financial services sector-however it is actively testing a number of pilots and starting to pay attention to the rapidly emerging technology (Coppi and Fast, 2019). This has been spurred on by both gray ${ }^{2}$ and academic literature highlighting the possible use cases and opportunities for social good (see Ko and Verity, 2016; Al-Saqaf and Seidler, 2017; Coppi and Fast, 2019).

In addition to documenting existing uses and conceptually exploring others, these reports and articles have begun grappling with some of the thornier issues the technology and its use presents. These include the right to privacy, the technology's ecological footprint, limitations on who has access to the technology and so on (Zambrano et al., 2017).

Despite this growing attention and accompanying literature, there has not been any specific attention paid to the pragmatic issues faced when using the emerging technology in an established international non-government organization (Coppi and Fast, 2019). This is critically important as many of the promises of blockchain technology will only eventuate in their fullest when whole ecosystems are using the technology. In other words, it will take the majority of stakeholders in any one market (or sector of society) to be part of a blockchain ecosystem for the greatest benefits of the technology to be realized. To get there requires a transition period from existing business processes to an integrated market sector and it is this transition period that holds the key to success for organizations exploring the technologyin other words, the critical question is how well new applications built on blockchain technologies accommodate existing processes built for legacy applications.

As the technology is increasingly used by organizations in the sector and by the broader community, it will be important to document and understand some of the challenges in using such a new technology so we can learn from the difficulties faced by others and avoid them in future applications of the technology (Dodgson et al., 2018; Coppi and Fast, 2019).

Some of these challenges have been previously faced by the international humanitarian and development sector in the Information and Communications Technology for Development $(\text { ICT4D })^{3}$ approach [(Keijdener et al., 2018); see (Yonazi, 2012) for a specific example from Tanzania]. This approach has been to explore different technologies to solve specific development

\footnotetext{
1"Blockchain technology" and "blockchain" will be used interchangeably throughout this paper. The authors acknowledge that blockchains are only one form of distributed ledger technology however "blockchain" will be used instead of the more accurate "distributed ledger technologies" both for simplicity's sake and due to the greater familiarity of the term.

2"Gray" literature refers to reports and papers produced by government, industry, community, and academia that are openly available but have not been published in academic literature.This can also include academic articles that have not been published, government reports, presentations, and evaluation reports amongst many (Benzies et al., 2006).

3 "ICT4D" refers to Information and Communications Technology For Development, see https://www.ict4dconference.org/
}

problems, using technology for good (Heeks, 2008). Although this paper touches on some of the similar process challenges for working with technology in the sector, it highlights these and additional challenges faced with a technology that holds the potential to change how we organize society rather than just solving particular problems within society (Scott, 2016).

This paper fills a gap in the literature regarding business processes and the non-technological challenges to implementing blockchain for social good projects. It does this by documenting the experiences and internal institutional challenges faced by Oxfam Australia as the organization explores blockchain technology through various proofs of concept and pilot projects.

\section{BACKGROUND AND RATIONALE}

Oxfam is an international non-government organization that works toward a just world without poverty (Oxfam, n.d.). Oxfam takes a human rights based approach to its work in advocacy, international development and humanitarian crises. Oxfam globally has a wealth of experience in understanding and working with power in all its expressions. Oxfam has a long history of working respectfully alongside communities to further their own ambitions. Oxfam already works as a broker and facilitator within and across networks and partnerships. Oxfam has strong and sophisticated advocacy, campaigning, and influencing approaches that work toward achieving a just world. It is in this light that Oxfam is exploring a technology that promises to shift power dynamics and which holds many opportunities to be used to address inequities and to support the empowerment of the disempowered.

Blockchain is a governance technology which enables revolutionary changes in how decisions are made and how society is organized (Allen et al., 2018). Oxfam is exploring blockchain technologies because of its potential to change power dynamics and address inequities. As blockchain technologies become ever more present in society, Oxfam must engage with their development and impact on society in keeping with Oxfam's overarching goals of eliminating poverty and addressing inequalities (Oxfam, n.d.). The likely changes instigated by the increasing use of blockchain in both the international development sector and in broader society require a (re) focus on some foundational questions in how societies develop and which possibilities are brought forward (Swan and de Filippi, 2017). One of the big questions is: who will realize these possibilities and how?

Oxfam has been innovating in the humanitarian sector for many years, trying new and different ways to have a positive impact on people affected by humanitarian crises. It was in this light that Oxfam began exploring blockchain technologies for social good. Oxfam does not subscribe to a humanitarian neophilia approach to innovation (Scott-Smith, 2016) but rather continuously scans the horizon for new and emerging technologies that may help us achieve our vision and aims - a just world without poverty. Oxfam takes an evidencebased approach to all our work and thus we have done so with blockchain technology, embarking on a journey to test specific 
use cases of the technology to determine whether continued exploration and scaling of pilots would contribute to our vision and aims across a variety of programmatic themes.

Oxfam is working in partnerships to actively explore six different use cases of blockchain globally. These initiatives are each at concept or pilot stage, considering the novelty of the technology, however most have plans to go to scale based on successful results of the pilots:

- BlocRice: a mobile app that uses blockchain technology to address gaps in the verification of organic rice from production to consumer. The app aims to empower farmers with real-time information on rice prices to improve their bargaining position and may be a much cheaper social certification mechanism (in comparison to FairTrade and similar certifications).

- The strawberry supply chain: a mobile app that provides consumers with a transparent and accessible certification that producers are treating laborers fairly, their produce is authentic, and the supply chain meets ethical standards.

- Smart donations: working with the OxChain initiative in exploring the fundraising opportunities blockchain may bring by developing and testing smart contracts that enable, for the first time, conditional giving.

- Weather risk index insurance: using smart contracting to automate anticipatory payments to small scale farmers when adverse weather conditions are predicted.

- Intra-office transfers: exploring blockchain-based methods of transferring value more often than actual money between Oxfam and partner offices around the globe.

- Cash transfer programming: a blockchain-based application to address shortcomings in current cash transfer platforms such as costly reconciliations, multi-organization coordination, traceability, and transparency of funds transfers.

This paper explores the challenges faced by Oxfam Australia in designing and implementing a blockchain-based cash transfer pilot project in a small island developing state. This project is an exemplar for Oxfam's broader experience in testing the technology in the projects outlined above however it emerged through a slightly different innovation process.

\section{DESCRIPTION OF CASE AND METHODOLOGICAL ASPECTS}

The case documented in this paper emerged from Oxfam Australia's Innovation Lab. This OxLab's focus was on exploring different ways of working across the organization, drawing in cross-functional teams to work on specific projects. Concept notes for new projects were proposed and cross-functional teams coalesced around the detailed design of the selected projects-this project was one such case. Staff from the banking, humanitarian, technical advisor, international development programming, design, and IT units participated in this OxLabs to scope, design, and deliver a cash transfer project using blockchain technology. Although physically located off-site, the OxLabs project remained reliant on many existing Oxfam support services, such as the accounting, digital, and contract management business services.

The case documented in this paper is a traditional cash transfer project (Cash Learning Partnership, 2018). It differs only in the use of digital vouchers managed using blockchain technology. Others have tested blockchain technology in cash transfer programs, such as the World Food Programme (2017) Building Blocks and World Vision's Sikka (Davis, 2018). This Oxfam pilot differs in some important aspects which will become clear in the following brief description of the case.

Oxfam had an existing cash transfer project in a small island developing state that was the scaffold for the blockchain pilot. This approach of testing an additional aspect of an existing project was selected due to time and resource constraints however proved beneficial to the test case as the impact of using blockchain technology could be isolated from the impacts of a more traditional cash and voucher project. Furthermore, the extensive stakeholder engagement from the existing cash transfer project could be leveraged for the blockchain pilot, ensuring there were no surprises for observing and participating stakeholders. Oxfam worked with the technology provider to design and implement community awareness material that was used to engage two separate communities in the pilot. Oxfam worked closely with the leadership of the two communities to identify over twenty smallholder shops willing to participate in the trial along with just under two hundred households. Physical cards with NFC chips (unlike the World Vision trial) were distributed to registered community members and smartphones were distributed to the shopkeepers. No biometric information was taken in the registration of pilot participants (unlike the WFP trial). Transactions were recorded on the Ethereum blockchain and able to be tracked in real-time. Detailed results and lessons from the blockchain-based cash transfer project will be shared publicly at a later date.

This paper focuses on the internal institutional challenges Oxfam Australia has experienced and thus the considerations one should take in to account when further exploring blockchain technology in the international development and humanitarian sector.

\section{DISCUSSION AND LESSONS LEARNED}

\section{Awareness}

Many of the difficulties faced by Oxfam and the project team that will be described below have at their foundation a lack of awareness and understanding of what blockchain technology is, how it works and can be used, and the myriad issues its use raises.

When the project team started to engage with internal stakeholders to explore possible blockchain use cases, it became clear there was a large knowledge gap related to the technology. Although many internal stakeholders were initially excited about the project, it became clear that this was partly due to the timing of the project's inception at the end of 2017, at the peak of the blockchain hype curve (Linden and Fenn, 2003). The implications of this were that many stakeholders were understandably confused about the distinction between the technology and the cryptocurrency use case. To enhance internal 
engagement (with the view that this is the first step toward garnering internal support), the project team spent significant time educating internal stakeholders about the basics of the technology, including clarifying that Oxfam was not in any way going to be using, buying or selling cryptocurrencies [in contrast to organizations such as UNICEF, see (UNICEF, n.d.)]. Although clearly necessary, this stage of building internal engagement was unexpectedly time consuming, requiring effort and resources to garner organizational support for the initiative to proceed.

As engagement improved, internal support also increased for the project. However, as the project progressed it became clear that the internal support required was more than just backing but also technical in nature. The specifics of these technical requests are detailed below however a related aspect was the support required to work through the myriad ethical and human rights issues the technology surfaces. For example, the project team needed guidance on the technology's compliance with GDPR however this was not available internally because the regulation is so new (Berberich and Steiner, 2016). Importantly, many of the human rights and ethical issues associated with blockchain are also being worked through by various other sectors globally, with no standards or rules yet emerging (Ahram et al., 2017).

Finally, the experience of the Oxfam project team highlighted that low levels of awareness and understanding of the technology meant that it was considered by some internal stakeholders as too risky to continue exploring. The push-back centered on the idiom that there were too many unknowns about the technology and thus any investments in the technology at such an early stage of its development were likely to be money wasted. This critique of the project holds some legitimacy due to Oxfam's financial base being almost exclusively public monies, of which Oxfam has a moral obligation to use for the greatest impact [this relates to broader debates about the role of innovation in the public sector, see (Scott-Smith, 2016)]. However, it also speaks to the necessary awareness raising required on the benefits and risks of a new technology for informed decision making-an important lesson learnt. After this hurdle was passed, the project team were given senior leadership backing and unfettered access to internal support services. When the concept progressed to implementation, further lessons emerged as the use of blockchain technology challenged traditional internal systems and processes.

\section{Support}

As mentioned above, the low levels of technical understanding of blockchain meant that the right type of technical support services were not available to the Oxfam project team. This came to the fore as awareness increased internally - the more one knows, the more one realizes how much one does not know! To progress the project, technical support was requested from the IT department, the ICT4D unit, the legal department, the finance department, the public engagement team, and the humanitarian section. The novelty of blockchain technology ensured knowledge gaps in each department, not for their lack of competency but for the newness of the technology and the nascent understanding in each industry of its relevant impacts.

To emphasize, blockchain technology is barely one decade old however is complex in its architecture, its applications, and its implications (Nelson, 2018). The various sections within Oxfam deal with incredible complexity in their various fields day-in, day-out. The Oxfam project team's requests for technical support for the blockchain-based cash transfer pilot project added to this complexity, asking each section to grapple with unfamiliar complicated issues within a very short time frame. Once the sections understood enough about the technology and the project to know how they may provide assistance, some recognized that they did not have the in-house capacity to provide such services and thus recommended external support, either from academic or private sector partners.

For example, the Oxfam project team required IT advice on the hosting architecture proposed by the project's private sector partner to help determine whether the proposal was value for money. The request concerned the requirements to host nodes as part of the proposed private, permissioned blockchain to be used and whether it was feasible for these nodes running specific software to be hosted by Oxfam's internal network. Being such a new and niche area, Oxfam's IT section were unfamiliar with both the broader blockchain technology and with the specific hosting software required so they suggested seeking professional external advice. However, the cost and availability of this external advice was prohibitive. This, in addition to the time required to understand the specifications and broker the relationship between the private sector partner and the internal IT section, resulted in project delays.

A similar process was experienced with the contracting and legal aspects to the project. Again, the use of the technology presented new and unfamiliar legal challenges which required external support. For example, one challenging question was which laws were to apply to the contract, not only because of the dispersed geographic locations of the contracting partners but also because of uncertainty as to where, physically, the data was held (Berberich and Steiner, 2016). One of blockchain's strengths is that nodes that hold copies of the chain are geographically dispersed however this challenges ideas of data ownership and the implications of such, e.g., which data privacy laws should apply?

\section{Non-traditional Partnerships}

The examples of technical support requested above highlight another challenge faced by the Oxfam project team in exploring blockchain technology in this particular use case: navigating nontraditional partnerships. Oxfam and many organizations within the international development and humanitarian sectors are increasingly working with the private sector. The experience of this project highlighted just how diverse the private sector is and some of the challenges associated with working with small startup tech companies that do not yet have proven track records, are unfamiliar with institutional donor compliance and have structurally different motivations.

Oxfam's experience in this project has been different than most previous engagement with the private sector, which has focused on either strengthening markets, influencing behavior, and/or fundraising. Oxfam in this project has been working with predominantly small start-up companies that do not have experience in complying with foreign aid stipulations and public 
expectations of managing donations. Furthermore, the project team has experienced difficulty, at times, in negotiating contracts and ways of working with companies whose experience and expectations of such are somewhat different than those in the international development and humanitarian sector. Specifically, it has been challenging to navigate value for money questions and ensuring contracting relationships are equitable.

Finally, it has been challenging working with a technology that facilitates and, perhaps, encourages collaboration in a sector which is traditionally competitive. The Oxfam project is funded by foreign aid money, which is awarded on a competitive basis. The incentive thus exists for anything developed from the pilot project to be a proprietary product of Oxfam's however this is counter to the possibilities inherent in the technology. In other words, it has been challenging for the project team to guard the development of the blockchain-based cash transfer platform to ensure Oxfam's comparative advantage whilst also engaging the sector to garner the greatest impact from the platform's use. This tension also exists when considering next steps after the pilot project - which business case is most appropriate for the product to go to scale, keeping in mind organizational pressure to increase and expand revenue streams but also as Oxfam acknowledges the greatest benefit in using the application will only emerge if it is used by as many cash transfer actors as possible (and thus the need to reduce barriers to use as low as possible, including cost).

Finally, the tension between collaboration and competition is also borne out of sharing learnings from the pilot project. Oxfam is committed to widely sharing as much as possible about the workings of the pilot project, its impacts and the challenges found during its implementation however this may put Oxfam at a comparative disadvantage. This is further complicated by the aforementioned challenge of working with the private sector, who must (structurally) keep their comparative advantage should they wish to succeed as a business.

\section{CONCLUDING REMARKS}

As society adopts the technology more widely and at deeper levels, how it works with existing systems and processes will become a more prominent question. This paper has provided an overview of the six live pilot projects that Oxfam is conducting using blockchain technologies. For one of the six pilot projects, we have documented some of the challenges faced by Oxfam Australia as it explores blockchain technologies in the international development and humanitarian sector with

\section{REFERENCES}

Ahram, T., Sargolzaei, A., Sargolzaei, S., Daniels, J., and Amaba, B. (2017). "Blockchain technology innovations," in 2017 IEEE Technology and Engineering Management Conference (TEMSCON) (San Jose, CA), 137-141.

Allen, D., Berg, C., and Novak, M. (2018). Blockchain: an entangled political economy approach. J. Public Finance Public Choice 33, 105-25. doi: $10.1332 / 251569118 \times 15282111163993$

Al-Saqaf, W., and Seidler, N. (2017). Blockchain technology for social impact: opportunities and challenges ahead. J. Cyber Pol. 2, 338-354. doi: $10.1080 / 23738871.2017 .1400084$ the aim of highlighting some specific answers to this question. Many of the challenges experienced, including grappling with data privacy and protection, organizational risk aversion, IT infrastructure, legal, and donor compliance are most likely common and hence our lessons learned will be useful to Oxfam and other international development and humanitarian organizations projects exploring the technology.

To conclude, we recommend the following next steps:

- Greater collaboration across the international humanitarian and development sector, globally and regionally, to better learn from the various explorations of blockchain technology

- Further analytical research on non-technological and internal business process challenges in exploring, implementing, and shaping the development of blockchain technologies

- Further emphasis on improving education that is accessible regarding the nuances of the technology and the issues and opportunities it raises, especially for those staff with strategic responsibilities

- Further emphasis on business processes within organizations (such as legal agreements, accounting procedures), especially within the sector, to enable and provide supporting environments for exploring, implementing and shaping blockchain and other emerging technologies

- Further emphasis on innovation within the international development and humanitarian sector to address systemic issues through transformational changes in addition to transactional improvements in products and services.

\section{DATA AVAILABILITY}

All datasets generated for this study are included in the manuscript and/or the supplementary files.

\section{AUTHOR CONTRIBUTIONS}

$\mathrm{JH}$ wrote the first draft of the manuscript. EC contributed to manuscript revision, read, and approval. Both are key members of the project team.

\section{FUNDING}

The pilot project described in the article was funded by the Australian Government's Department of Foreign Affairs and Trade through the Australian NGO Cooperation Program (ANCP). 
Davis, J. (2018). Sikka: Working at the Intersection of Blockchain and Humanitarian Innovation. Medium. Available online at: https://medium.com/@davisjef/sikkaworking-at-the-intersection-of-blockchain-and-humanitarian-innovation2c752332c616 (accessed April 25, 2018).

Dodgson, K., Baynham-Herd, Z., and Symons, K. (2018). Blockchain and Global Challenges: A Roadmap for NGOs. Edinburgh Futures Institute Paper.

Heeks, R. (2008). ICT4D 2.0: the next phase of applying ICT for International development. Computer 41, 26-33. doi: 10.1109/MC. 2008.192

Keijdener, M. N. C., Overbeek, S. J., and España, S. (2018). "Scalability factors in an ICT4D context : a literature review. Part of book," in Proceedings of the 5th International Symposium "Perspectives on ICT4D" (P-ICT4D 2018) Co-Located with 10th ACM Web Science Conference (WebSci'18), Amsterdam, May 27, 2018. Available online at: http://dspace.library.uu.nl/handle/1874/369707

Ko, V., and Verity, A. (2016). BlockChain for the Humanitarian Sector Future Opportunities. Digital Humanitarian Network, 2016. Available online at: https://drive.google.com/file/d/0B-8okvw4smiNnFEWjF1M2NSaW8/view? usp $=$ sharingandusp $=$ embed_facebook

Linden, A., and Fenn, L. (2003). Understanding Gartner's Hype Cycles. Strategic Analysis Report N ${ }^{\circ}$ R-20-1971. Gartner, Inc.

Nelson, P. (2018). Primer on Blockchain: How to Assess the Relevance of Distributed Ledger Technology to International Development. USAID. Available online at: https://www.usaid.gov/sites/default/files/documents/15396/USAIDPrimer-Blockchain.pdf

Oxfam. (n.d.) Our Purpose and Beliefs $\mid$ Oxfam International. Available online at: https://www.oxfam.org/en/our-purpose-and-beliefs (accessed April 29, 2019).

Scott, B. (2016). How Can Cryptocurrency and Blockchain Technology Play a Role in Building Social and Solidarity Finance? UNRISD, Working Paper, 26.
Scott-Smith, T. (2016). Humanitarian neophilia: the 'innovation turn' and its implications. Third World Quart. 37, 2229-2251. doi: 10.1080/01436597.2016.1176856

Swan, M., and de Filippi, P. (2017). Toward a philosophy of blockchain: a symposium: introduction. Metaphilosophy 48, 603-619. doi: $10.1111 /$ meta. 12270

UNICEF (n.d.). Donate in Crypto. n.d. Available online at: https://www.unicef.org. nz/donate-in-crypto

World Food Programme (2017). Blockchain Against Hunger: Harnessing Technology In Support Of Syrian Refugees. Available online at: https:// www.wfp.org/news/news-release/blockchain-against-hunger-harnessingtechnology-support-syrian-refugees

Yonazi, J. (2012). Exploring facilitators and challenges facing ICT4D in Tanzania. J. E-Government Stud. Best Pract. 2012, 1-16. doi: 10.5171/2012.703053

Zambrano, R., Kris Seward, R., and Sayo, P. (2017). Unpacking the Disruptive Potential of Blockchain Technology for Human Development. Available online at: http://hdl.handle.net/10625/56662

Conflict of Interest Statement: The authors declare that the research was conducted in the absence of any commercial or financial relationships that could be construed as a potential conflict of interest.

Copyright $(0) 2019$ Hallwright and Carnaby. This is an open-access article distributed under the terms of the Creative Commons Attribution License (CC BY). The use, distribution or reproduction in other forums is permitted, provided the original author(s) and the copyright owner(s) are credited and that the original publication in this journal is cited, in accordance with accepted academic practice. No use, distribution or reproduction is permitted which does not comply with these terms. 